\title{
Short-term forecasting in road evacuation: calibration of a travel time function
}

\author{
G. Musolino \& A. Vitetta \\ Università degli Studi Mediterranea di Reggio Calabria, \\ DIMET - Dipartimento di Informatica, Matematica, Elettronica \\ e Trasporti, Italy
}

\begin{abstract}
The paper presents a framework to define a function for estimating within-day variations of travel time on a network. The framework integrates two main components: a within-day traffic assignment model, that simulates the interaction between travel demand flows and the road transport network, and a dynamic vehicle routing model that provides optimal routes of emergency vehicles. The variable linking the two models is the short-term forecasted travel time, making it possible to capture anticipatory information on traffic dynamics on the network in evacuation conditions.
\end{abstract}

Keywords: within-day traffic assignment, dynamic vehicle routing, short-term forecasting.

\section{Introduction}

Correct information about travel time on a transport network is important to plan optimal Vehicle Routing (VR). In congested urban networks this is a binding task both in ordinary conditions for freight vehicles in order to perform efficient delivery and pick-up operations (e.g. to adhere to strict time windows) and in evacuation conditions (e.g. when a population has to be evacuated due to an approaching calamitous event) for emergency vehicles in order to allow people and goods to be rescued. In the former case the goal is to reduce costs of freight transport, while in the latter case it is to mitigate risk for people and goods. ITS technology enables real-time information on travel times to be provided on some network elements (links, paths, ...). However, it is necessary both to cover the non-monitored elements of the network and to have reliable forecasted travel 
times that users will experience during their trip. The question is somewhat complex and has been the subject of extensive studies, with a view to developing a sophisticated architecture consisting of technological and simulation tools able to support real-time management and control of traffic conditions on a network.

This paper, though recalling some elements developed in the above contexts, focuses on the specific problem concerning the estimation of time-varying travel times that represent the input for a dynamic vehicle routing design algorithm, which, in turn, generates routes for a fleet of emergency vehicles on an urban network in evacuation conditions.

Vehicle route design models and algorithms in the literature generally assume exogenous costs of the road transport network. On the other hand, the variability conditions of the network and of travel demand during evacuation result in appreciable variations in travel time of vehicles that cannot be neglected.

From the above considerations, there emerged the need to integrate the vehicle route design models in the literature with dynamic traffic assignment models, in order to take into account the effects of variation in network and travel demand within the vehicle routing design process.

The paper presents a general framework which integrates two main components:

- a Dynamic Traffic Assignment (DTA) model, that simulates the interaction between travel demand flows and the road transport network in order to estimate time-varying travel times and vehicular flows on a network;

- a Dynamic Vehicle Routing (DVR) model, that provides emergency vehicle routes taking into account the time-varying travel times.

The aims of our paper are the following:

- to propose a framework for supporting emergency vehicle routing design on an urban road network, taking into account time-varying traffic conditions;

- to specify and calibrate a travel time function able to capture anticipatory information on traffic dynamics expressed through short-term forecasted travel times;

- to test the general framework on a real experimental area in order to validate the results through observed data.

The proposed framework could be considered the core of a decision support system for real-time management of a fleet of emergency vehicles on an urban road network in evacuation conditions.

This work is part of research project SICURO carried out by the Laboratory for Transport Systems Analysis (LAST) of the Mediterranea University of Reggio Calabria (Italy). The general objective of the project was risk mitigation in urban areas in terms of exposure through the definition and implementation of evacuation procedures $[1,2]$. The results concern the development of models [3$6]$, procedures $[7,8]$ and guidelines $[9,10]$ to support transport planning in evacuation conditions.

The paper is structured in three sections. Section 2 reports a classification concerning DTA models, highlighting current research directions. Sections 3 presents a framework that allows optimal routes to be defined for vehicles on a 
network, taking into account the within-day variations of travel time. Section 4 describes preliminary results conducted on a real experimental area and some conclusions are finally reported.

\section{Classification of DTA models}

Several architectures to support real-time management of traffic conditions on a network have been proposed [11, 12]. Amongst others, we focus on two modelling components: (i) models to estimate and forecast within-day (and dayto-day) time-varying travel times; (ii) models able to define optimal paths and routes for users according to predefined objectives.

Among the several issues involving transportation systems planning in evacuation conditions, these components have become increasingly important to support the mitigation of the population's exposure to an approaching calamitous event. The above two elements have been the focus of several studies in recent decades. Below, an overview of DTA principles is presented through some reference papers.

Traffic assignment models are generally subdivided into Static (STA) and Dynamic (DTA) models. STA models simulate the so-called user equilibrium condition, where link (or path) flows and travel costs are mutually consistent. This condition, if reached, will persist as long as the network and the travel demand do not change, because the single user has no incentive to change his/her path. Although it is an abstract concept, equilibrium ensures a reasonable approximation of user behaviour and mathematical properties (e.g., existence and uniqueness of equilibrium). In DTA models, by simulating the interactions between the time-varying network and travel demand, the assumption of steadystate traffic conditions is removed, allowing transport system evolution to be represented as in the case of evacuation conditions when travel demand peaks, temporary capacity variations, queue formation and dispersion occur. The concept of equilibrium can formally be extended, or not, to the dynamic context, according to the treatment of travel time in the (pre-trip) path choice dimension:

- instantaneous travel times on the network are those at departure time without considering subsequent modifications during the trip;

- experienced travel times on the network are those revealed and experienced during the trip.

In the first case users can reconsider the possibility of changing paths during the trip (en-route choice), while in the second case users anticipate future traffic conditions that they will face during the trip. Equilibrium-seeking DTA models ensure that users with the same departure time between the same origindestination pair, but choosing different paths, have the same experienced travel time [13].

DTA models can also be classified into analytical and simulation-based models [14]. The former approximate the problem with a system-wide (system optimum) or individual (user equilibrium) objectives, through mathematical formulations and explicit constraints. Yet they represent user behaviour and traffic dynamics in a simplified way. The latter are able to reproduce via 
simulation the complex inter-temporal demand-supply interactions between time-varying travel demand and the transport network. However, their outputs depend on a large amount of inputs and parameters that need to be estimated. Simulation-based models are generally grouped according to their level of aggregation of user behaviour into macroscopic, mesoscopic and microscopic.

Due to their potential, DTA models have been used to simulate transport systems in evacuation conditions. Three Mile Island accident prompted the development of a first generation of models in USA during the 1980s, which sought to introduce dynamics by applying static models to sub-intervals of the reference period. After 9/11, research received a new impetus and a second generation of simulation-based models were proposed due to increasing computational burdens.

As mentioned above, calibration of DTA models is still an open issue, mainly because they require data recorded over extended periods, and there are few studies in the literature. The lack of experience is more evident in simulating transport systems in evacuation conditions. This is due to two reasons. The first is operational: collecting field data is both burdensome and costly, because human behaviour cannot be monitored in real evacuations and because it is expensive to set up a real-world evacuation experiment. The second is conceptual: human behaviour in an experiment is not the same as that in a real evacuation, because, in the first case, people are aware that there is no real disaster approaching. There is a debate about the validity of field data collected in real-world evacuation experiments. In our opinion DTA models need to be calibrated and validated against field data, even if they come from a real-world evacuation experiment.

The literature concerning applications of DTA models in simulating evacuation conditions can be classified according to three purposes, namely demand management, network design and simulation of an evacuation plan. Demand management applications concern departure time definition to reduce congestion and evacuation times [15-17]. Network design applications concern path optimization and management [18-20]. Some papers focus on supply management through operations like contra flow [21, 22] and ramp metering [23] to improve network capacity during evacuation. The effectiveness of evacuation plans was verified for urban areas [24-26] and for industrial areas [27].

\section{Proposed framework}

This section proposes a framework to define analytic functions to forecast within-day variations of travel time suitable for emergency vehicle route design. The ability to design vehicle routes in a dynamic context has two main implications:

- the availability of periodically updated short-term forecasts of experienced travel times on the network;

- the dynamic extension of traditional static vehicle routing algorithms (see [28]). 


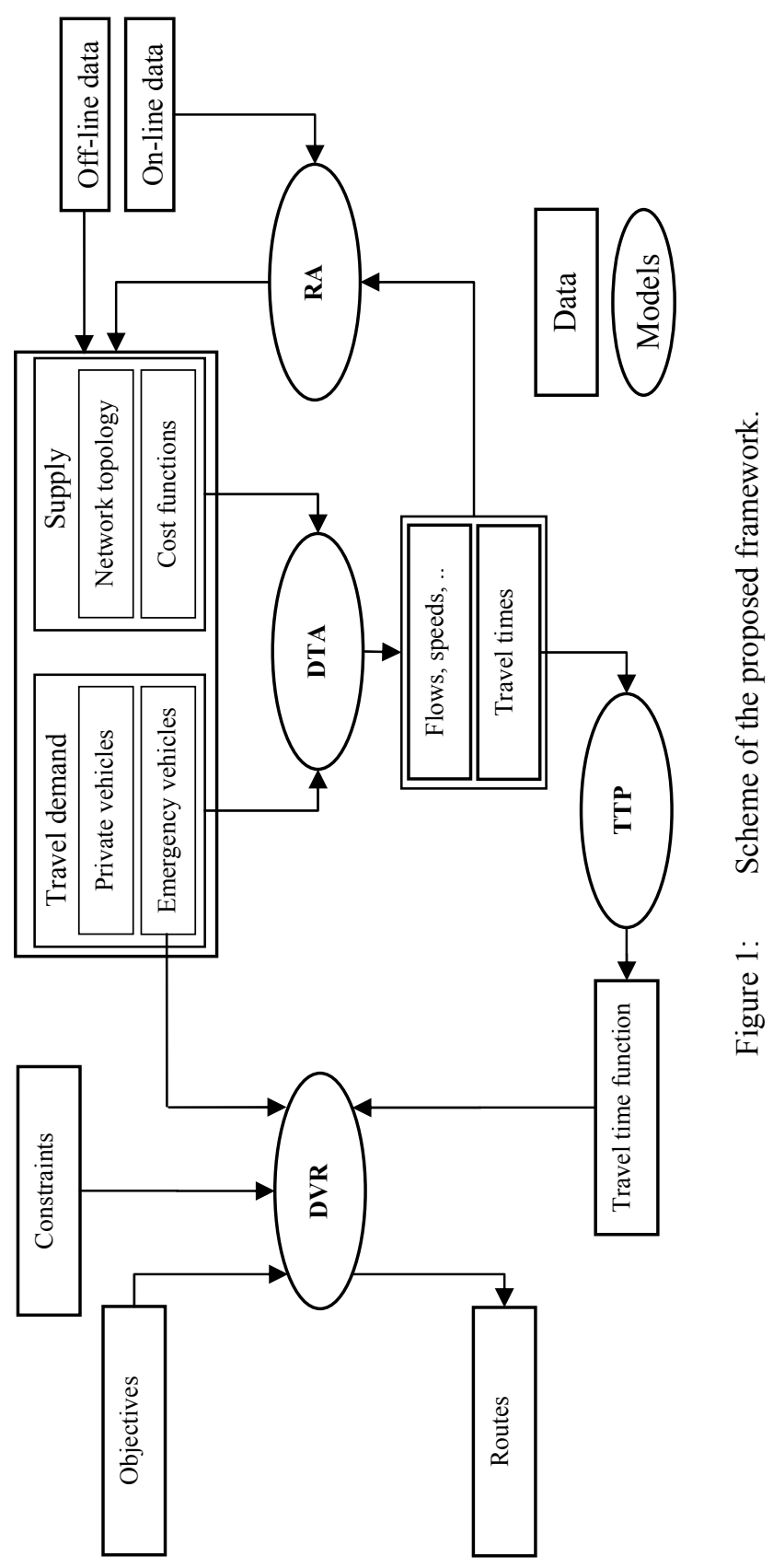


The general framework integrates four main modules (Figure 1):

- a RA (Reverse Assignment) module, which receives current (on-line) and historical (off-line) data concerning travel demand and network and adjusts DTA model parameters until DTA model outputs approximate online data [29];

- a DTA module, which receives adjusted travel demand and network data and provides an estimation of time-varying travel times of vehicles on the network;

- a TTP (Travel Time Predictor) module, which receives the time-varying link travel times and provides a calibrated continuous travel time function;

- a DVR module, which receives demand flows concerning emergency vehicles and the calibrated continuous travel time function, and provides optimal routes for emergency vehicles, given some objectives and constraints.

The RA module contains an optimization model which minimizes the distances between the on-line flows and simulated flows and between on-line travel times and travel times as outputs of the DTA model [29].

Off-line and on-line data support DTA model calibration in two different ways. Off-line data include time-varying O-D flows, path choice model and cost function parameters, parameters used in the RA module. The resulting off-line parameters of the DTA model are consistent with expected traffic conditions in a planned scenario. On-line data are typically vehicular flows, speeds and travel times, which are made available by the use of ITS technologies. They allow the DTA model to capture revealed unexpected traffic conditions generated by events that cannot be completely defined in a planned scenario.

The TTP module is necessary to have forecasts on a short-term horizon (1015 minutes) concerning travel times on a link. It is possible to supply the dynamic vehicle routing algorithm with anticipatory information.

The different modules of the framework broadly work in time according to the concept of rolling horizon, schematically depicted in Figure 2.

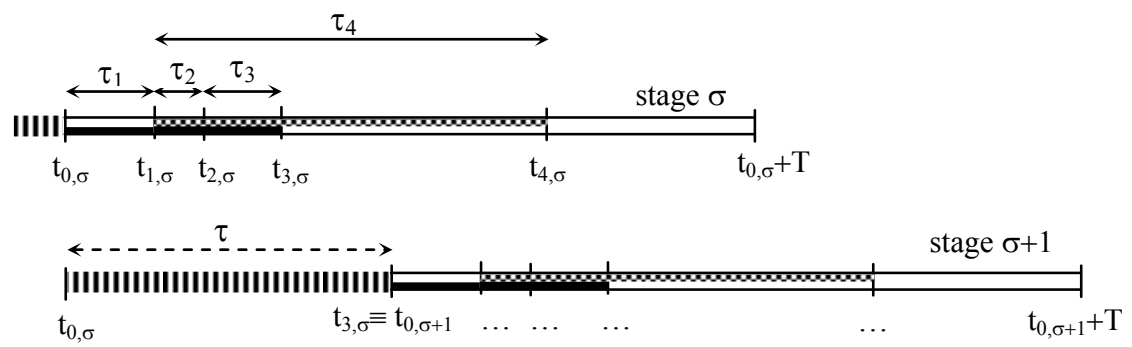

Figure 2: $\quad$ Temporal sequence of models [11, 12].

The framework is completely deployed at every stage of length $\mathrm{T}$ (50-60 minutes). Assuming stage $\sigma$ has been reached, on-line data are available at instant $t_{0, \sigma}$. The modules are sequentially applied: the iterative sequence of DTA- 
RA modules is processed in a time $\tau_{1}$; the TTP module is processed in a time $\tau_{2}$ and the DVR in a time $\tau_{3}$. It is worth noting that the reliability of forecasted traffic conditions on the network (time-varying travel times), as provided by the DTA-RA modules, progressively diminishes from a maximum at instant $t_{1, \sigma}$ to a minimum after a time $\tau_{4}$ (instant $t_{4, \sigma}$ ). Therefore, updated (real-time) data must be available after a time $\tau$, which represents the roll period, that must be between $t_{1, \sigma}$ and $t_{4, \sigma}$, unless loosing every confidence on the forecasted travel times. After time $\tau$, a new stage $\sigma+1$ starts and the above sequence is repeated.

\section{Experimental application}

An experimental application allowed individual modules of the proposed general framework to be validated, focusing on the sequence of the DTA, TTP and DVR modules (see Figure 1). This section presents some preliminary results concerning the DTA and TTP modules.

\subsection{DTA module: travel time estimation}

The experimental application was carried out in the urban area of Melito di Porto Salvo (Italy), where an incident involving a heavy vehicle was simulated. As the potential disaster was announced, the evacuation of people living and working in the surrounding area took place and a fleet of emergency vehicles started to rescue those who were unable to evacuate by themselves [30]. The whole set of evacuation operations, executed according to the municipal evacuation plan, were monitored and evaluated [31-33].

A portion of the road network was equipped with a surveillance system able to store data concerning vehicular flows, speeds and densities. The above data allowed calibration and validation of the network model $[8,34]$, while a travel demand model was calibrated in order to estimate evacuation travel demand due to the incident occurrence [35-37].

A simulation-based DTA model reproduced the demand-supply interaction mechanisms $[6,8]$ : vehicle dynamics on links and nodes were simulated with disaggregate (microscopic) cost functions and pre-trip path choices were

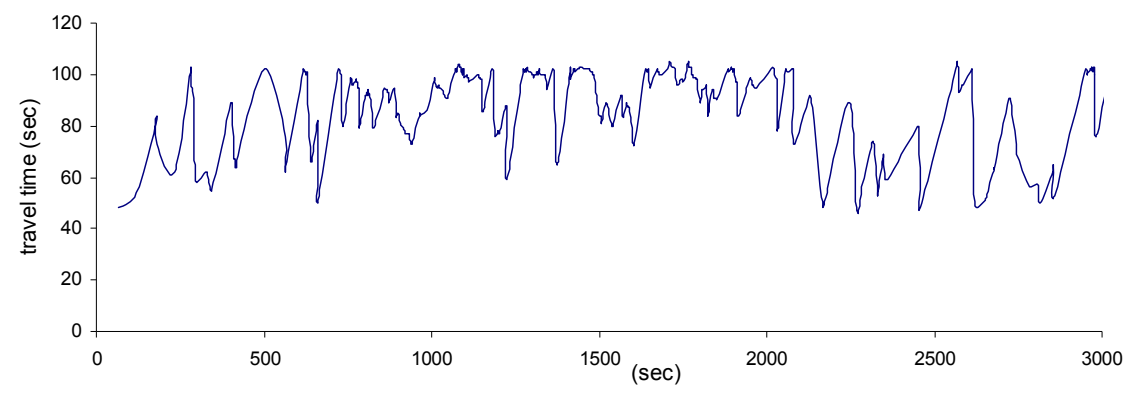

Figure 3: $\quad$ Experienced travel times of vehicles traversing the link. 
simulated through a C-logit model [38]. One of the outputs provided by the DTA model is the travel time, $\mathrm{tt}_{\mathrm{i}, \mathrm{a}}^{\mathrm{DTA}}(\mathrm{t})$, that each vehicle $\mathrm{i}$ entering at time $\mathrm{t}$ on link $\mathrm{a}$ will experience. An example is reported in figure 3.

\subsection{TTP module: travel time function calibration}

The TTP module contains an optimization model which minimizes the differences between travel times obtained with the DTA model and those with a travel time function to be specified and calibrated. The function must satisfy two requirements: (i) to fit statistically the realization of travel times estimated by the DTA model and (ii) to ensure finding in a closed form an optimal value for the waiting time of emergency vehicles along their route. At the current stage of the research, the function is specified as follows:

$$
\mathrm{tt}_{\mathrm{i}, \mathrm{a}}(\beta ; \mathrm{t})=\left(\beta_{1} \mathrm{w}_{a}+\beta_{2} \sin \left(2 \pi \mathrm{t} / \beta_{3}\right)\right) \mathrm{l}_{a} \quad \forall \mathrm{a} \in \mathrm{G} ; \forall \mathrm{i} \in \mathrm{f}_{\mathrm{a}}
$$

where

$\mathrm{tt}_{\mathrm{i}, \mathrm{a}}(\beta ; \mathrm{t})$ is the travel time of vehicle $\mathrm{i}$ entering at time $\mathrm{t}$ on link $\mathrm{a}$;

$\mathrm{w}_{a}$, the available width of link $\mathrm{a}$;

$1_{a}$, the length of link a;

$\mathrm{t} \in[0, \mathrm{~T}]$, an instant belonging to the simulation time period $\mathrm{T}$ (which can coincide with the stage length);

$\beta=\left[\beta_{1} \beta_{2} \beta_{3}\right]^{\mathrm{T}}$, the vector of parameters to be calibrated;

$\mathrm{G}$, the network graph;

$\mathrm{f}_{\mathrm{a}}$, the number of vehicles travelling on link a in time period $\mathrm{T}$.

In eq (1) the quantity inside the brackets has the dimension of travel time per unit of length, where

- $\quad \beta_{1} \mathrm{w}_{a}$ is a static term depending on the link geometry (width);

- $\quad \beta_{2}$ and $\beta_{3}$ are respectively the amplitude and the period of a dynamic term capturing the time-dependent variations of travel time.

Parameters of eq (1) are calibrated through the optimization model (least square method), which minimizes the distance between travel times estimated by the DTA model, $\mathrm{tt}_{\mathrm{i}, \mathrm{a}}^{\mathrm{DTA}}$, and those from eq (1):

$$
\text { objective : minimize } \sum_{\mathrm{a} \in \mathrm{G}} \sum_{\mathrm{i} \in \mathrm{fa}}\left(\mathrm{p}_{\mathrm{i}}\left(\mathrm{tt}_{\mathrm{i}, \mathrm{a}}^{\mathrm{DTA}}-\mathrm{tt}_{\mathrm{i}, \mathrm{a}}(\boldsymbol{\beta})\right)\right)^{2}
$$

variables: $\beta=\left[\beta_{1} \beta_{2} \beta_{3}\right]^{\mathrm{T}}$

with $\mathrm{p}_{\mathrm{i}}$ a weight function which measures the confidence of travel times provided by the DTA module

$$
\mathrm{p}_{\mathrm{i}}=\mathrm{p}(\mathrm{t})=\exp (-\alpha \mathrm{t}) \quad \forall \mathrm{t} \in\left[0, \tau_{4}\right]
$$

where $\alpha$ is a decay parameter and $\tau_{4}$ is the time interval as defined in figure 2 . The results of the calibration are presented in Table 1 . The parameter value of 
the static term $\beta_{1}$ sets an average level of travel time on each link, according to its available width. Values of parameters $\beta_{2}$ and $\beta_{3}$ of the dynamic term provide its contribution through periodic oscillations of travel time.

Table 1: $\quad$ Calibrated parameters of eq (1).

\begin{tabular}{cccc}
\hline $\begin{array}{c}\beta_{1} \\
{[\mathrm{sec} / \mathrm{m}]}\end{array}$ & $\begin{array}{c}\beta_{2} \\
{[\mathrm{sec} / \mathrm{m}]}\end{array}$ & $\begin{array}{c}\beta_{3} \\
{[\mathrm{sec}]}\end{array}$ & $\rho^{2}$ \\
\hline 31.48 & -8.62 & 20.05 & 0 \\
\hline$(22.66)$ & $(-1.01 *)$ & $(69.48)$ & 0.26 \\
\hline (t-student), *not significant at $95 \%$ level &
\end{tabular}

\section{Final remarks}

The paper presents a framework to support emergency vehicle routing design, taking into account within-day variations of travel time on an urban road network. The framework integrates a within-day traffic assignment model, that simulates the interaction between time-varying travel demand flows and network costs, and a dynamic vehicle routing model, that provides optimal routes of emergency vehicles. The core of the paper concerns the definition of a travel time function able to provide short-term forecasted values, which is the linking variable between the two above elements of the framework. The travel time function is specified and calibrated on data obtained from an experimental test site and it is used in [28]. Future work will concern further specifications and calibrations in order to better capture the variability of travel time and the validation of other framework modules.

\section{References}

[1] Russo F. \& Vitetta A., Risk evaluation in a transportation system. International Journal of Sustainable Development and Planning, 1 (2), pp. 170-191, 2006.

[2] Russo F. \& Vitetta A., Safety of users in road evacuation: General methodology and main results. Proc. of Urban Transport XIII, Urban Transport and the Environment in the 21st century, Brebbia C.A. (ed.), WIT Press, Southampton, pp. 763-772, 2007.

[3] Russo F. \& Chilà G., Safety of users in road evacuation: demand models. Proc. of Urban Transport XIII, Urban Transport and the Environment in the 21st century, Brebbia C.A. (ed.), WIT Press, Southampton, pp. 773-782, 2007.

[4] Russo F. \& Chilà G., Safety of users in road evacuation: RP vs. SP surveys in demand analysis. Proc. of Urban Transport XIV, Urban Transport and the Environment in the 21st century, Brebbia C.A. (ed.), WIT Press, Southampton, pp. 703-713, 2008.

[5] Vitetta A., Quattrone A. \& Polimeni A., Safety of users in road evacuation: design of path choice models for emergency vehicles. Proc. of Urban 
Transport XIII, Urban Transport and the Environment in the 21st century, Brebbia C. A. (ed.), WIT Press, Southampton, pp. 803-812, 2007.

[6] Vitetta A., Musolino G. \& Marcianò F.A., Safety of users in road evacuation: Supply and demand-supply interaction models for users. Proc. of Urban Transport XIII, Urban Transport and the Environment in the 21st century, Brebbia C.A. (ed.), WIT Press, Southampton, 2007.

[7] Vitetta A., Quattrone A. \& Polimeni A., Safety of users in road evacuation: algorithms for path design of emergency vehicles, Proc. of Urban Transport XIV, Urban Transport and the Environment in the 21st century, Brebbia C.A. (ed.), WIT Press, Southampton, pp. 727-737, 2008.

[8] Vitetta A., Musolino G. \& Marcianò F. A., Safety of users in road evacuation: calibration of cost functions and simulation. Proc. of Urban Transport XIV, Urban Transport and the Environment in the 21st century, Brebbia C. A. (ed.), WIT Press, Southampton, pp. 715-725, 2008.

[9] Russo F. \& Rindone C., Safety of users in road evacuation: planning internal processes and guidelines. Proc. of Urban Transport XIII, Urban Transport and the Environment in the 21st century, Brebbia C.A. (ed.), WIT Press, Southampton, pp. 825-834, 2007.

[10] Russo F. \& Rindone C., Safety of users in road evacuation: the logical framework approach in evacuation planning. Proc. of Urban Transport $X I V$, Urban Transport and the Environment in the 21st century, Brebbia C.A. (ed.), WIT Press, Southampton, pp. 751-760, 2008.

[11] Ben-Akiva M., Bierlaire M., Burton D., Koutsopoulos H. N. \& Mishalani R., Network State Estimation and Prediction for Real-Time Traffic Management. Networks and Spatial Economics, 2001, Volume 1, 3-4, 293-318.

[12] Mahmassani H. S., Dynamic Network Traffic Assignment and Simulation Methodology for Advanced System Management Applications. Networks and Spatial Economics, 2001,Volume 1, 3-4, 267-292

[13] TRB, A Primer for Dynamic Traffic Assignment. ADB30 Transportation Network Modeling Committee Transportation Research Board, 2010

[14] Peeta S. \& Ziliaskopoulos A.K., Foundations of Dynamic Traffic Assignment: The Past, the Present and the Future. Networks and Spatial Economics, 2001. 1(3-4): pp. 233-265.

[15] Mitchell S.W. \& Radwan E., Heuristic prioritization of emergency evacuation staging to reduce clearance time. In Transportation Research Board 85th CD-ROM, 2006.

[16] Sbayti H. \& Mahmassani H. S., Optimal scheduling of evacuation operations. In Transportation Research Record (1964), Transportation Research Board, Washington, D.C., 2006, pp. 238-246.

[17] Liu Yue, Chang G.L. \& Li Y., A corridor-based emergency evacuation system for Washington D.C.: system development and case study. In Transportation Research Board 87th Annual Meeting Compendium of Papers, Washington, D.C., 2008.

[18] Russo F. \& Vitetta A., Urban road transportation analysis in emergency conditions: models and algorithms. In Proceedings of Urban Transport 
2000, Sucharov and Brebbia C. A. (eds), WIT Press Boston, 2000, pp. 533-542.

[19] Cova T. J. \& Johnson J. P., A network flow model for lane-based evacuation routing. In Transportation Research Part A, Vol. 37A, 2003, pp. 257-275.

[20] Yuan F., Han L.D., Chin S.M. \& Hwang H., Proposed framework of simultaneous optimization for evacuation traffic destination and route assignment. In Transportation Research Record (1964), Transportation Research Board, Washington, D.C., 2006, pp. 50-58.

[21] Tuydes H. \& Ziliaskopoulos A., Network re-design to optimize evacuation contraflow. In Transportation Research Board, 83rd Annual Meeting Compendium of Papers CD-ROM, Washington, D.C., 2004.

[22] Theodoulou G. \& Wolshon B., Alternative methods to increase the effectiveness of freeway contraflow evacuation. In Transportation Research Record (1865), Transportation Research Board, Washington, D.C., 2004, pp. 48-56.

[23] Gomes G. \& May A., A microsimulation of a congested freeway using VISSIM. In Transportation Research Board, 83rd Annual Meeting, Compendium of Papers CD-ROM, Washington, D.C., 2004.

[24] McGhee C.C. \& Grimes M.C., An operational analysis of the Hampton roads hurricane evacuation traffic control plan. In Transportation Research Board 86th Annual Meeting CD-ROM, Washington, D.C., 2007.

[25] Kwon E. \& Pitt S., Evaluation of emergency evacuation strategies for downtown event traffic using a dynamic network model. In Transportation Research Record (1922), Transportation Research Board, Washington, D.C., 2005, pp. 149-155.

[26] Pel A. J. \& Bliemer M. C. J., Evacuation Plan Evaluation: Assessment of Mandatory and Voluntary Vehicular Evacuation Schemes by means of an Analytical Dynamic Traffic Model. In Transportation Research Board 87th Annual Meeting, Compendium of Papers DVD, Washington, D.C., 2008.

[27] Jha M., Moore K. \& Pashaie B., Emergency evacuation planning with microscopic traffic simulation. In Transportation Research Record (1886), Transportation Research Board, Washington, D.C., 2004, pp. 40-48.

[28] Polimeni A. \& Vitetta A., Dynamic vehicle routing in road evacuation: a model for route design. Proc. of Urban Transport XVII, Urban Transport and the Environment in the 21st century, Brebbia C. A. (ed.), WIT Press, Southampton, 2011.

[29] Russo F. \& Vitetta A., Reverse assignment: calibrating link cost functions and updating demand from traffic counts and time measurements. Inverse Problems in Science \& Engineering, ISSN 1741-5977 print/ISSN 1741-5985 Taylor \& Francis DOI: 10.1080/17415977.2011.565339, 2011.

[30] Vitetta A., Quattrone A. \& Polimeni A., Safety of users in road evacuation: Modelling and DSS for paths design of emergency vehicles. Proc. of Sustainable Development and Planning IV, vol.1, Brebbia C. A. (ed.), WIT Press, Southampton, pp. 485-495, 2009. 
[31] Russo F. \& Rindone C., Safety of users in road evacuation: Modelling and DSS for LFA in the planning process. Proc. of Sustainable Development and Planning IV, vol.1, Brebbia C.A. (ed.), WIT Press, Southampton, pp. 453-464, 2009.

[32] Russo F. \& Rindone C., Evaluation methods for evacuation planning. Proc. of Urban Transport XVI, Urban Transport and the Environment in the 21st century, Brebbia C.A. (ed.), WIT Press, Southampton, pp. 335-343, 2010.

[33] Russo, F. \& Rindone C., Data Envelopment Analysis (DEA) for evacuation planning. Proc. of Risk analysis VII \& Brownfields V, Brebbia C.A. (ed.), WIT Press, Southampton, pp. 455-467, 2010.

[34] Vitetta A., Musolino G. \& Marcianò F.A., Safety of users in road evacuation: Modelling and DSS for transport supply and supply-demand interaction. Proc. of Sustainable Development and Planning IV, vol.1, Brebbia C. A. (ed.), WIT Press, Southampton, pp. 475-484, 2009.

[35] Russo F. \& Chilà G., Safety of users in road evacuation: Modelling and DSS for demand. Proc. of Sustainable Development and Planning IV, vol.1, Brebbia C.A. (ed.), WIT Press, Southampton, pp. 465-474, 2009.

[36] Russo F. \& Chilà G., Dynamic approaches to demand model in evacuation conditions. Proc. of Urban Transport XVI, Urban Transport and the Environment in the 21st century, Brebbia C.A. (ed.), WIT Press, Southampton, pp. 303-312, 2010.

[37] Russo F. \& Chilà G., A sequential dynamic choice model to simulate demand in evacuation conditions. Proc. of Risk analysis VII \& Brownfields $V$, Brebbia C.A. (ed.), WIT Press, Southampton, pp. 431-442, 2010.

[38] Russo, F., and A. Vitetta. An assignment model with modified Logit, which obviates enumeration and overlapping problems, Transportation, vol. 30, 2003, pp. 177-201. 